\title{
Breast and Cervical Cancer Screening Among Women in Jordan: Findings from the Behavioural Risk Factor Surveillance System - 2007
}

\author{
Mohannad Al Nsour ${ }^{*}, 1$, David W Brown ${ }^{2}$, Mohammed Tarawneh ${ }^{1}$, Raja Haddadin ${ }^{1}$ and Henry Walk ${ }^{3}$ \\ ${ }^{I}$ Ministry of Health, Jordan \\ ${ }^{2}$ The Brown Consulting Group, Charlotte, North Carolina, USA \\ ${ }^{3}$ Centers for Disease Control and Prevention, Atlanta, USA
}

\begin{abstract}
Introduction: Breast cancer is the most common cancer among women in Jordan. Age standardized incidence rate for cervical cancer has been estimated at 3.6 per 100,000 women. This report presents the results of breast and cervical cancer screening practicesamong a nationally representative sample of Jordanian women aged 35 years or above.

Method: We used data from the third Jordan Behavioural Risk Factor Surveillance System (2007) among a nationally representative sample of Jordanian women aged $\geq 35$ years $(n=1,157)$. Logistic regression was used to examine the associations between each of breast and cervical cancer screening practices and selected socio-demographic characteristics.

Results: Only $12.4 \%$ of women aged 35 years or older reported ever having a mammography. One fifth reported ever having a clinical breast examination at least once in their life time. Over one quarter $(27.1 \%)$ of the women reported that they perform self-breast examination on monthly basis, and $41.7 \%$ reported ever having performed a self-breast examination. Among ever-married women aged 35 years or more, Pap smear test was performed by $27.8 \%$ during their life. The reported low practices have shown substantial differences across regions, age groups, level of education, family income, marital status, and source of medical services.

Conclusion: The low reported cancer screening activities among women in Jordan calls for action. Data on current screening practices is a primary step to provide health professionals, and policy-makers with the information necessary to identify priorities and to facilitate cancer control, policy development, and planning.
\end{abstract}

Keywords: Breast self-examination, clinical breast examination, Jordan, mammography, population-based study, screening cancer, women.

\section{INTRODUCTION}

Worldwide, breast cancer is a major public health problem with in estimated 1.38 million women diagnosed with breast cancer each year and more than half a million cases of deaths [1]. Breast cancer is the most common cancer among women in Jordan, accounting for more than a third of all female cancers. In 2008, the median age at diagnosis of breast cancer among women was 51 years, and the agestandardized incidence of breast cancer among women was 50.4 per 100,000 . The incidence of female breast cancer is increasing; in 2008 the crude incidence rate was 30.2 per 100,000 compared to 22.9 per 100,000 in 2001 [2].

Cervical cancer is the third most common cancer in women worldwide with nearly 500,000 new cases each year and more than 250,0000 deaths annually [1]. More than $80 \%$ of cervical cases occurred in developing countries [3]. Information from low and middle-income countries has shown a growing burden of the disease as an important cause of premature death among women with substantial negative

*Address correspondence to this author at the Ministry of Health, Jordan; Tel: +962 6 5655086; Fax: +96265655089;

E-mail: mohannadnsour973@yahoo.com implications for quality of life $[4,5]$. In Jordan, it has been estimated that each year 61 women (age standardized incidence rate 3.6 per 100,000 women) are diagnosed with cervical cancer and 35 women (age standardized death rate 1.9 per 100,000 women) die from the disease [6].

Despite their importance, breast and cervical cancer screening programmes in Jordan are not well established and do not effectively reach the majority of women throughout the country. Data collection on current screening practices is an important step to demonstrate current gaps in service utilization, and to provide health professionals, researchers and policy-makers with the information necessary to identify priorities and to facilitate cancer control, policy development, and planning in Jordan. In this study, we aim to report on the prevalence of practicing mammography, clinical breast examination, self-breast examination and Papanicolaou testing among Jordanian women aged 35 years or older. In addition, we examine associations between these cancer screening practices and selected socio-demographic characteristics.

\section{METHODS}

Since 2002, the Jordan Ministry of Health in collaboration with the World Health Organization (WHO) and the Centers for Disease Control and Prevention (CDC) 
has established a Behavioural Risk Factor Surveillance System (BRFSS) to collect data on many of the behaviours and conditions that place adults (age $\geq 18 \mathrm{y}$ ) at risk for noncommunicable diseases. The latest (third survey) survey was conducted in 2007 among a nationally representative sample of Jordanian adults aged $\geq 18$ years. The sampling frame was stratified by governorate and urbanity ending up with 30 strata that fit within three regions: North, Middle, and South. A sample of 461 blocks was selected systematically with probability proportional to size. Eight random households were selected from each block. From each sampled household, one respondent aged 18 years or older was selected randomly and interviewed face to face using a validated Arabic closed ended questionnaire, which was tested on a pilot sample. All reported estimates were weighted to account for the sample design. Of the total 3,688 sampled households that were selected, 3654 adults were successfully interviewed, resulting in a response rate of $99.1 \%$. In this survey (2007), only women aged 35 years or above were asked about cancer screening practices. Moreover, for cultural reasons, only married women aged 35 years or above were asked how long it had been since their last Papanicolaou test. Women with a past history of hysterectomy were excluded from the analysis. As a result, 1,157 women were included in the study analysis for breast cancer screening practices, and 1,018 for Papanicolaou test.

The survey questionnaire was adapted from the WHO Stepwise Surveys and United States Behavioural Risk Factor Surveillance System (BRFSS) survey instrument. The questionnaire included questions on demographics (e.g., age, gender, and educational status), health care access, noncommunicable diseases, various behavioural risk factors, and use of medical services. In addition, the 2007 survey included questions about cancer screening practices among women based on the country need. These questions were asked for women aged 35 years or above. Female respondents were asked the following questions, "How long has it been since you last had a mammogram?" with a possible response set of "Less than 6 months", "6 months to less than 12 months", "12 months to less than 2 years", "2 years to less than 3 years", "5 or more years", "Never", "Don't Know/Not sure". An indicator variable was then created for whether women had ever had a mammogram (yes/no). Similarly, questions were asked for ever having a CBE (yes/no), ever conducting a SBE (yes/no), and ever having a Pap smear (yes/no). The reliability of breast cancer screening questions and their construct validity are described elsewhere $[7,8]$.

Fieldwork was conducted between June 1 and August 23, 2007. All field teams included trained female interviewers and a local health official to facilitate communication. Consents were obtained either verbally or by signing a written statement.

Stata/SE version 10 was used in the analysis and accounted for the complex sampling design of the BRFSS. Logistic regression was used to examine the associations between each of these screening practices (as a result, four logistic regression models were created) and selected sociodemographic characteristics. A relative standard error of greater than $30 \%$ was used to exclude estimates that were unstable (due to small sample size). A formal consent from the Primary Health Care Administration of the Jordanian Ministry of Health was obtained to use the data.

\section{RESULTS}

The sample characteristics of women aged 35 years or older are shown in Table 1 . The mean age of participants was 50 years (SD 12.0). Overall, nearly two thirds of women $(61.8 \%)$ resided in the middle region of the country, two thirds of women were aged less than 55 years, $42 \%$ had no or low levels of education, almost $60 \%$ reported middle income levels (100-299 JDs), the majority of women were unemployed $(91.1 \%)$, and three quarters were currently married. Three quarters of women reported general good health status. Two thirds $(67.0 \%)$ reported having health insurance, and $54 \%$ reported receiving their medical care in Ministry of Health facilities (Table 1). The lifetime prevalence of mammography among women aged 35 or older in Jordan was $12 \%$. Women with high levels of education (23.8\%), higher levels of income (19.2\%) as well as those who worked $(20.9 \%)$ and who received health care from teaching hospitals $(41.1 \%)$ were more likely to have received a mammogram than their respective counterparts. Differences in mammography practices were observed across regions of the country being highest in the Middle $(13.5 \%)$ compared to the North (11.9\%) and South (7.1\%).

A quarter of women reported having had clinical breast examination at least once during their lifetime. Women with levels of income greater than $300 \mathrm{JD}$ per month were more likely to have clinical breast examinations $(37.6 \%)$, as were women whose primary source of health care was a teaching hospitals or the private sector; $(56.7 \%)$ and $(36.3 \%)$ respectively. Clinical breast examination was low in the southern region $(14.9 \%)$ compared to the northern region $(25.1 \%)$ and middle region $(26.8 \%)$.

About one quarter $(27.1 \%)$ of women reported performing self-breast examination on a monthly basis, and $41.7 \%$ reported performing a self-breast exam at least once during their lifetime. Self-breast examination was less common among older women, while self-breast examinations were more common among women with higher levels of education, high income, and women who worked. A greater prevalence of self-breast examination was observed among women without health insurance $(48.9 \%)$ compared to women with health insurance $(38.1 \%)$. The prevalence of self breast examination was more common among women residing in the Middle (45.1\%) and North $(39.2 \%)$ regions than in the South $(27.8 \%)$.

Among ever-married women aged 35 years or more in Jordan, the lifetime prevalence of Pap smear was $27.8 \%$. The highest prevalence $(35.8 \%)$ was reported among women aged 35-44 years old while the lowest $(11.0 \%)$ was reported among women aged 65 years or older. The prevalence of at least one Pap smear (lifetime prevalence) was greater among women with high levels of education, women who worked, and women with high levels of income. The prevalence was also greater among women whose primary source of health care was the private sector compared to those receiving health care from other sources (Table 2). 
Table 1. Sample Characteristics of Jordanian Women Aged 35 Years or Older $(n=1,157)$, Behavioral Risk Factor Surveillance Survey - Jordan, 2007

\begin{tabular}{|c|c|c|}
\hline Variable & Number (\%) & $\mathbf{S E}^{*}$ \\
\hline \multicolumn{3}{|l|}{ Region } \\
\hline North & $319(28.1)$ & 1.3 \\
\hline Middle & $672(61.8)$ & 1.4 \\
\hline South & $166(10.1)$ & 0.8 \\
\hline \multicolumn{3}{|l|}{ Age (years) } \\
\hline $35-44$ & $470(40.0)$ & 1.5 \\
\hline $45-54$ & $297(25.8)$ & 1.3 \\
\hline $55-64$ & $221(19.5)$ & 1.2 \\
\hline $65+$ & $169(14.7)$ & 1.1 \\
\hline \multicolumn{3}{|l|}{ Education } \\
\hline Never attended school & $325(28.0)$ & 1.3 \\
\hline Primary school & $403(34.8)$ & 1.4 \\
\hline Secondary/tech school & $374(32.3)$ & 1.4 \\
\hline Higher education & $55(4.7)$ & 0.6 \\
\hline \multicolumn{3}{|l|}{ Family Income (JD) } \\
\hline$<100$ & $162(14.4)$ & 1.1 \\
\hline $100-299$ & $662(59.8)$ & 1.5 \\
\hline 300 and above & $287(25.8)$ & 1.3 \\
\hline \multicolumn{3}{|l|}{ Working status } \\
\hline Yes & $95(8.1)$ & 0.8 \\
\hline No & $1062(91.9)$ & 0.8 \\
\hline \multicolumn{3}{|l|}{ Marital status } \\
\hline Married & $873(75.4)$ & 1.3 \\
\hline Not married & $284(24.6)$ & 1.3 \\
\hline \multicolumn{3}{|l|}{ General health status } \\
\hline Good conditions & $879(76.1)$ & 1.3 \\
\hline Fair or poor & $277(23.9)$ & 1.3 \\
\hline \multicolumn{3}{|l|}{ Health insurance } \\
\hline Yes & $793(67.0)$ & 1.4 \\
\hline No & $364(33.0)$ & 1.4 \\
\hline \multicolumn{3}{|l|}{ Source of medical service } \\
\hline Ministry of Health & $628(54.3)$ & 1.5 \\
\hline Royal Medical Services & $213(17.6)$ & 1.1 \\
\hline UNRWA** & $81(7.5)$ & 0.8 \\
\hline Private Sector & $230(20.4)$ & 1.2 \\
\hline
\end{tabular}

Some categories do not total $100 \%$ because of rounding.

*SE, standard error.

** UNRWA: The United nations Relief Works Agency.

Table 3 displays associations between cancer screening practices among women in Jordan and selected sociodemographic variables. Women living in the south were less likely (ranging from 44\%-53\%) to undergo any breast screening practices compared to women living in the other regions. Women aged 55 or older were about $50 \%$ less likely to perform self-breast examination (SBE) and have a Pap smear than women aged 35-44 years (P-value 0.001, and Pvalue $=0.000$, respectively). Women with secondary or higher level of education were twice as likely to receive a clinical breast examination $(\mathrm{P}$-value $=0.001)$, and to perform selfbreast examination compared to women with a primary level of education or less $(\mathrm{P}$-value $=0.000)$. Women reporting an income of 100-299 JDs were 1.6 times more likely to undergo a mammogram than women having an income of less than 100 JDs $(P$-value $=0.017)$. Similar results were observed for women undergoing a Pap smear $(\mathrm{OR}=2$; $\mathrm{P}$ value 0.017$)$. Women with an income of $300 \mathrm{JDs}$ or more were 2 times more likely to perform self-breast examination $(\mathrm{P}$-value $=0.043)$ and were 4 times more likely to undergo a Pap smear than women reporting less than 100 JDs (p-value $0.000)$. Unmarried women were less likely to perform selfbreast examination than married women (P-value 0.04). Women utilizing private medical services were 1.6 time more likely to undergo a clinical breast examination ( $\mathrm{p}$-value 0.015 ) and were 1.5 times more likely to undergo Pap smear than women receiving their medical care from the Ministry of Health. Working status, general health status, and health insurance were not found to be related to undergoing any of the screening practices.

\section{DISCUSSION}

This report presents the results of the third Behavioural Risk Factor Surveillance System (BRFSS) (2007) among a nationally representative sample of Jordanian women aged $\geq 35$ years and their breast and cervical cancer screening practices. In this population-based study, which allowed examination across regions and population subgroups of the Jordanian population, the prevalence of breast and cervical cancer screening practices among Jordanian women were low with substantial differences across geographic regions and selected socio-demographic characteristics. The population and behavioural characteristics of the sample were similar to those of other national surveys in Jordan [9, $10]$.

The low prevalence of using mammography could be partially attributed to a low knowledge or low level of awareness about the importance of mammography among Jordanian women (35\%) [11]. According to Petro-Nustas, about one fourth of women do not believe in mammogram benefits [12]. Disparities in the use of mammography across regions in Jordan were observed and could be partly explained by differences in factors associated with utilization of screening services (e.g., education, income) [13-17] and inequalities in availability and affordability [18] as women with poor access to health facilities are much less likely to undergo mammography $[16,17]$.

A mammogram in Jordan is still an opportunistic healthcare service. Since 2008, the Ministry of Health started a program for providing the mammogram services for different regions in the country; nowadays, the mammogram services are available in fourteen health facilities in the middle, seven in the northern, and six in the southern parts of 
Table 2. Mammography, CBE, SBE, Pap Smear Among Women Aged 35 Years or Older, Behavioral Risk Factor Surveillance Survey - Jordan, 2007

\begin{tabular}{|c|c|c|c|c|c|c|c|c|}
\hline \multirow[t]{2}{*}{ Variable } & \multicolumn{2}{|c|}{$\underset{(n=1,157)}{\operatorname{Mammogram} \text { Ever }}$} & \multicolumn{2}{|c|}{$\begin{array}{l}\text { CBE Ever } \\
(\mathrm{n}=1,157)\end{array}$} & \multicolumn{2}{|c|}{$\begin{array}{l}\text { SBE Ever } \\
(n=1,157)\end{array}$} & \multicolumn{2}{|c|}{$\begin{array}{l}\text { Pap Smear Ever } \\
(\mathbf{n}=\mathbf{1 , 0 1 8})\end{array}$} \\
\hline & Number (\%) & SE & Number (\%) & SE & Number (\%) & SE & Number (\%) & SE \\
\hline \multicolumn{9}{|l|}{ Region } \\
\hline North & 37 (11.9) & 1.8 & $78(25.1)$ & 2.5 & $121(39.2)$ & 2.8 & $82(28.6)$ & 2.7 \\
\hline South & $11(7.1)$ & 2.1 & $23(14.9)$ & 2.9 & $45(27.8)$ & 3.6 & $28(18.6)$ & 3.2 \\
\hline \multicolumn{9}{|l|}{ Age (years) } \\
\hline $35-44$ & $50(11.3)$ & 1.5 & $138(30.7)$ & 2.2 & $235(51.2)$ & 2.3 & $149(35.8)$ & 2.4 \\
\hline $45-54$ & $40(14.1)$ & 2.1 & $72(25.4)$ & 2.6 & $138(49.3)$ & 3.0 & $76(29.8)$ & 2.9 \\
\hline Never attended school & $19(6.0)$ & 1.4 & $39(12.8)$ & 1.9 & $35(11.9)$ & 1.9 & $33(11.8)$ & 2.0 \\
\hline Primary school & $51(13.4)$ & 1.7 & $84(21.8)$ & 2.1 & $170(43.7)$ & 2.5 & $111(31.6)$ & 2.5 \\
\hline Secondary/tech school & $54(14.8)$ & 1.9 & $131(36.0)$ & 2.5 & $220(59.3)$ & 2.6 & $117(34.6)$ & 2.6 \\
\hline Higher education & $13(23.8)$ & 5.9 & $23(43.4)$ & 6.9 & $36(67.4)$ & 6.6 & $19(46.1)$ & 7.8 \\
\hline \multicolumn{9}{|l|}{ Family Income (JD) } \\
\hline$<100$ & $10(6.5)$ & 2.0 & $23(15.3)$ & 3.0 & $31(20.6)$ & 3.3 & $12(9.6)$ & 2.7 \\
\hline $100-299$ & $67(10.6)$ & 1.2 & $142(22.4)$ & 1.7 & $247(39.2)$ & 1.9 & $153(25.9)$ & 1.8 \\
\hline 300 and above & $53(19.2)$ & 2.4 & $104(37.6)$ & 2.9 & $162(57.7)$ & 2.9 & $103(41.4)$ & 3.2 \\
\hline \multicolumn{9}{|l|}{ Marital status } \\
\hline Not married & $29(10.9)$ & 1.9 & $48(17.9)$ & 2.4 & $70(26.7)$ & 2.7 & --------- & ----- \\
\hline \multicolumn{9}{|l|}{ General health status } \\
\hline Good conditions & $107(12.7)$ & 1.1 & $231(27.3)$ & 1.5 & $390(46.0)$ & 1.7 & $239(30.9)$ & 1.7 \\
\hline Fair or poor & $30(11.5)$ & 2.0 & $46(17.9)$ & 2.4 & $71(28.2)$ & 2.8 & $41(17.8)$ & 2.5 \\
\hline \multicolumn{9}{|l|}{ Health insurance } \\
\hline Yes & $83(10.9)$ & 1.1 & $179(23.9)$ & 1.6 & $288(38.1)$ & 1.8 & $181(26.0)$ & 1.7 \\
\hline No & $54(15.2)$ & 1.9 & $98(27.6)$ & 2.4 & $173(48.9)$ & 2.7 & $99(31.4)$ & 2.6 \\
\hline \multicolumn{9}{|l|}{ Source of medical service } \\
\hline Ministry of Health & $66(10.9)$ & 1.3 & $133(22.2)$ & 1.7 & $233(39.4)$ & 2.0 & $148(27.0)$ & 1.9 \\
\hline Royal Medical Services & $20(10.3)$ & 2.2 & $42(21.1)$ & 2.9 & $69(33.7)$ & 3.3 & $45(23.6)$ & 3.1 \\
\hline UNRWA* & $9(11.4)$ & 3.6 & $18(22.5)$ & 4.7 & $34(43.7)$ & 5.6 & $11(14.8)$ & 4.1 \\
\hline Teaching Hospitals & $5(41.1)$ & 14.2 & $79(56.7)$ & 14.4 & $8(65.3)$ & 13.9 & $3(27.3)$ & 13.8 \\
\hline Private Sector & $37(17.8)$ & 2.6 & $77(36.3)$ & 3.3 & $117(53.7)$ & 3.4 & $72(39.6)$ & 3.6 \\
\hline
\end{tabular}

SE, standard error.

Breast screening practices were perfomed among women aged 35 years or older $(n=1,157)$.

Pap smear was performed among ever- married women only aged 35 years or older, women with previous history of having hysterectomy were excluded from the analysis of Pap smear $(\mathrm{n}=1,018)$.

* UNRWA: The United nations Relief Works Agency. 
Table 3. Determinants of Undergoing Cancer Screening Practices Among Women Aged 35 Years or Older, Behavioral Risk Factor Surveillance Survey - Jordan, 2007

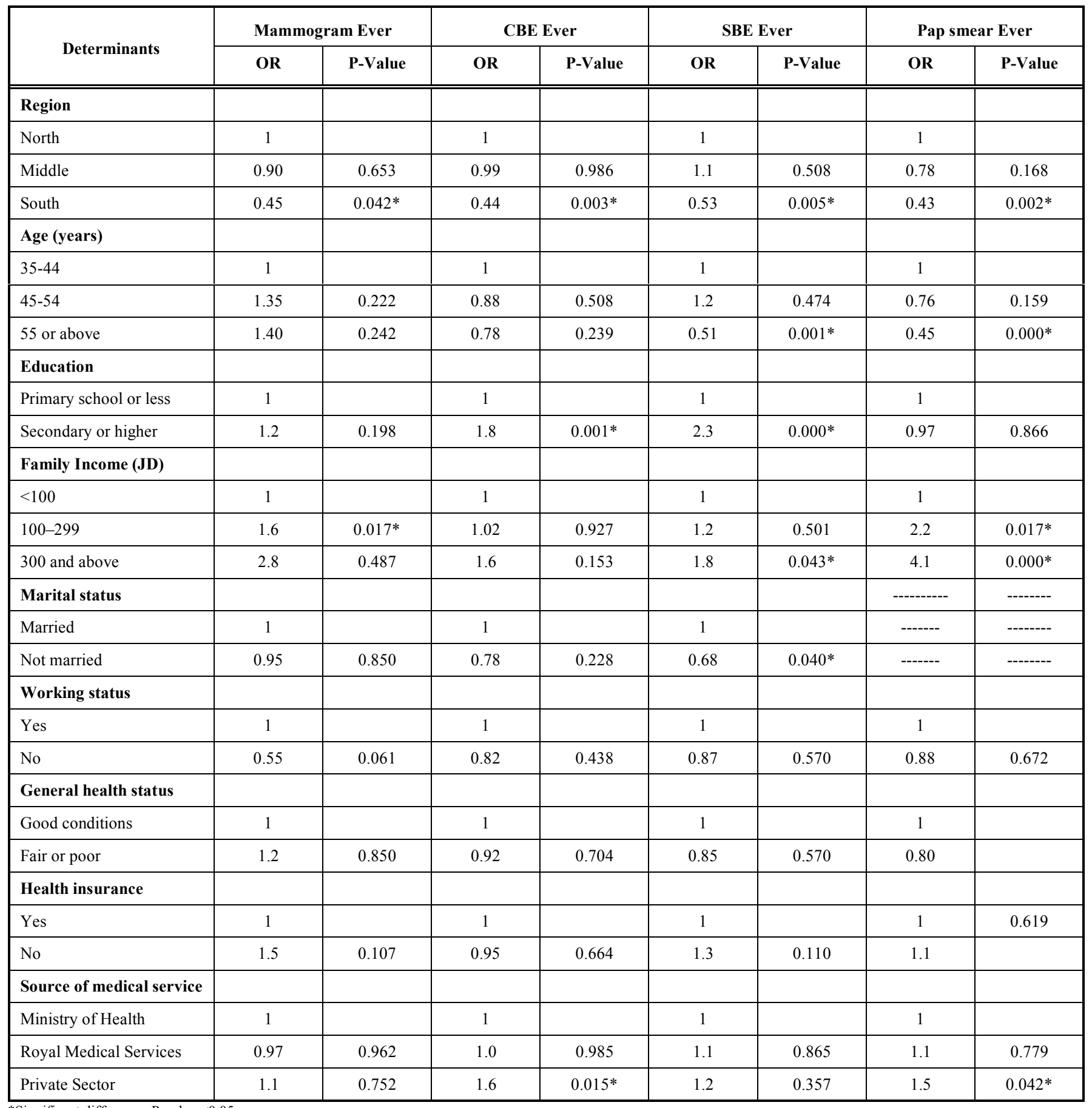

*Significant difference; P-value $<0.05$.

- SE, standard error.

- Breast screening practices were performed among women aged 35 years or older $(n=1,157)$.

- Pap smear was performed among ever- married women only aged 35 years or older, women with previous history of having hysterectomy were excluded from the analysis of Pap smear $(n=1,018)$.

the country. Unpublished data from the Ministry of Health shows that the percentage of received mammogram services was reported to be the lowest in the southern region. In four out of six mammogram units in this region, the number of received cases was zero mainly due to shortage of qualified trained staff. In Jordan, the majority of mammogram services are provided by the private sector and are centralized in the capital city (Amman).

Although $44.8 \%$ of Jordanian women are aware of clinical breast examination [11], we observed that only $25.1 \%$ of women reported having ever had a CBE. In Jordan, $\mathrm{CBE}$ was integrated into primary health care services during 
the last decade; becoming an important component of maternal and child health services that are provided free of charge regardless of one's health insurance. Nonetheless, women receiving care through the private sector reported the highest prevalence of $\mathrm{CBE}$. The low prevalence of $\mathrm{CBE}$ among women in Jordan might signal the need for raising awareness among health care professionals about the importance of performing clinical breast examinations with special attention paid to those who work in the southern region. Health care professionals should be encouraged to focus on older women and women with no formal education.

Despite several controversial studies on the benefits of self-breast examination as a screening tool, women are still encouraged to use it [19]. While the benefits of SBE remain unclear, women who practice SBE are more likely to go to for screening mammogram [20]. Prior reports suggest that approximately $70 \%$ of Jordanian women know about SBE [11]. The low prevalence of performing SBE on monthly basis observed in our data was consistent with studies from Jordan and elsewhere $[11,20,21]$. Similar to other studies, education and age were important factors associated with performing SBE [20, 22, 23]. In 2008, the National Jordan Breast Cancer programme launched the National Breast Cancer Screening and Diagnosis Guideline [24]. According to the guideline instructions, women should perform selfbreast examinations (SBE) starting in their adolescent years.

Little was known about utilization of Pap smear services in Jordan. In the present study, only $27.8 \%$ of married women reported having ever had a Papanicolaou test. Lack of awareness and understanding is perhaps one of the most important determinants of Pap smear screening. In fact, reports suggest that $67 \%$ to $75 \%$ of Jordanian women had never had heard of a Pap smear [25, 26]. Jordanian women who have had a Pap smear (most often on opportunistic basis [25] have a clear preference for a female doctor or a female nurse [26]. The low uptake of Pap smear could be due to the low incidence of cervix cervical cancer in Jordan and the fact that this disease is primarily caused by HPV infection which is a sexually transmitted disease and believed to be uncommon in a conservative Muslim country. Nonetheless, special attention should be given to the low Pap smear screening prevalence among women in Jordan and the establishment of a comprehensive program for the early detection and prevention of cervical cancer may be warranted. Such a program could be integrated into the National Jordan Breast Cancer Program; established in 2006 for breast cancer screening and early detection.

Our results should be interpreted in light of the following limitations. These data are self-reported. Conceivably, some respondents may have misreported their cancer screening practices either out of embarrassment or to provide a socially desirable response. Women were not asked to answer more detailed questions about screening practices.

Many researchers investigated the knowledge and estimated the prevalence of breast and cervical cancer screening among different communities. The knowledge about the screening methods of breast cancer was estimated in southeast Iran for married women aged 15-60 years with a mean age of 28.8 years. The women had relatively sufficient knowledge about breast self-examination and mammogram corresponding to $55.7 \%$ and $72.7 \%$ respectively [27]. Other researchers reported poor understanding and lack of awareness about risk factors and screening of breast cancer among samples of Asian women [20], and Pakistani women [21]. In Saudi Arabia, low knowledge of breast cancer risk factors among female secondary schools was demonstrated with $39.6 \%$ of female students stated ever hearing about breast self- examination [28].

With respect to performing the screening methods, generally, the use of the screening methods is low especially in low and middle income countries [29]. In southeast Iran only $4.1 \%$ had ever performed clinical breast examination, and $1.3 \%$ had ever had the mammogram. Furthermore, it was reported that $76.8 \%$ have never performed a breast self examination [26]. In a study from Pakistan, only $4.9 \%$ had performed a mammogram at some point in their life [20]. Studies from Qatar [30], and Kuwait [31] showed that $39.4 \%, 35.2 \%$, and $14.3 \%$ respectively had ever performed a Pap smear.

Advanced age, lower education level, insufficient health insurance, and lower income are all factors that may contribute to the poorer knowledge and prevalence of performing breast cancer and cervical screening tests. This finding was in parallel to other researches on Jordanian women [11, 23], Iranian women [26], Asian women [20], Qatari women [30], and Kuwaiti women [31].

In summary, these are among the most up-to-date estimates of breast cancer and cervical cancer screening practices in Jordan. The low prevalence of reported cancer screening activities among women in Jordan should serve as a call for action to policy makers and health care professionals working in the country. Finally, our data provide a foundation for evidence and result-based breast cancer screening programmes in Jordan and are an essential element for raising public awareness, advocacy, and improving service delivery. Continued monitoring and evaluation of breast and cervical cancer screening practices are essential to developing future targeted and effective programmes and policies in Jordan.

\section{ACKNOWLEDGEMENT}

Declared none.

\section{CONFLICT OF INTEREST}

None of the authors have any conflicts of interest to report.

\section{REFERENCES}

[1] Ferlay J, Shin HR, Bray F, Forman D, Mathers C, Parkin DM Estimates of worldwide burden of cancer in 2008: GLOBOCAN 2008. Int J Cancer 2010; 127(12): 2893-917.

[2] Jordan Cancer Registry, Directorate of Non-Communicable diseases, Ministry of Health, Jordan. Cancer Incidence in Jordan 2008, 2010.

[3] Sankaranarayanan R, Ferlay J. Worldwide burden of gynaecological cancer: the size of the problem. Best Pract Res Clin Obstet Gynaecol 2006; 20: 207-25.

[4] Sankaranarayanan R, Nene BM, Shastri SS, et al. HPV screening for cervical cancer in rural India. N Engl J Med 2009; 360: 138594.

[5] Sankaranarayanan R, Thara S, Esmy PO, Basu P. Cervical cancer: screening and therapeutic perspectives. Med Princ Pract 2008; 17: 351-64.

[6] Ferlay J, Shin HR, Bray F, Forman D, Mathers C, Parkin DM. GLOBOCAN 2008, Cancer Incidence and Mortality Worldwide: 
IARC Cancer Base No.10, Lyon, France: International Agency for Research on Cancer; 2010. Available from: http://globocan.iarc.fr

[7] Caplan LS, McQueen DV, Qualters JR, Leff M, Garrett C, Calonge N. Validity of women's self-reports of cancer screening test utilization in a managed care population. Cancer Epidemiol Biomarkers Prev 2003; 12: 1182-7.

[8] Vacek PM, Mickey RM, Worden JK. Reliability of self-reported breast screening information in a survey of lower income women. Prev Med 1997; 26: 287-91.

[9] Department of Statistics (Jordan). Population and family health survey 2007. Demographic and Health Surveys Macro International Inc. Calverton, Maryland USA. 2009.

[10] Centers for Disease Control and Prevention (CDC). Assessing risk factors for chronic disease - Jordan, 2004. MMWR Morb Mortal Wkly Rep 2006; 55(23): 653-5

[11] Ministry of Health (Jordan), Cancer Prevention Directorate. Knowledge, Practice, Attitude of Jordanian Women Towards Breast Cancer: A Cross-sectional Study. 2006.

[12] Petro-Nustas W. Jordanian women's health beliefs about mammography. J Community Health Nurs 2001; 18: 177-94.

[13] Flynn BS, Gavin P, Worden JK, Ashikaga T, Gautam S, Carpenter J. Community education programs to promote mammography participation in rural New York state. Preventive Med 1997; 26: 102-8.

[14] Mickey RM, Vezina JL, Worden JK, Warner SL. Breast screening behavior and interactions with health care providers among lower income women. Med Care 1997; 35: 1204-11.

[15] Potvin L, Camirand J, Béland F. Patterns of health services utilization and mammography use among women aged 50 to 59 years in the Quebec Medicare system. Med Care 1995; 33: 515-30.

[16] Schueler KM, Chu PW, Smith-Bindman R. Factors associated with mammography utilization: a systematic quantitative review of the literature. J Womens Health (Larchmt) 2008; 17: 1477-98.

[17] Von Euler-Chelpin M, Olsen AH, Njor S, Vejborg I, Schwartz W, Lynge E. Socio-demographic determinants of participation in mammography screening. Int J Cancer 2008; 122: 418-23.

[18] Adib SM, Sabbah MA, Hlais S, Hanna P. Research in action: mammography utilization following breast cancer awareness campaigns in Lebanon 2002-05. East Mediterr Health J 2009; 15: 6-18s.
[19] Del Giudice ME, Tannenbaum D, Goodwin PJ. Breast selfexamination: resistance to change. Can Fam Physician 2005; 51: 698-9.

[20] Sim HL, Seah M, Tan SM. Breast cancer knowledge and screening practices: a survey of 1,000 Asian women. Singapore Med J 2009; 50: $132-8$.

[21] Maqsood B, Zeeshan MM, Rehman F, et al. Breast cancer screening practices and awareness in women admitted to a tertiary care hospital of Lahore, Pakistan. J Pak Med Assoc 2009; 59: 418 21.

[22] Montazeri A, Vahdaninia M, Harirchi I, et al. Breast cancer in Iran: need for greater women awareness of warning signs and effective screening methods. Asia Pac Fam Med 2008; 7: 6.

[23] Petro-Nustus W, Mikhail BI. Factors associated with breast selfexamination among Jordanian women. Public Health Nurs 2002; 19: $263-71$.

[24] Jordan Breast Cancer Program. Breast Cancer Screening and Diagnosis Guidelines. 2008

[25] Amarin ZO, Badria LF, Obeidat BR. Attitudes and beliefs about cervical smear testing in ever-married Jordanian women. East Mediterr Health J 2008; 14: 389-97.

[26] Maaita M, Barakat M. Jordanian women's attitudes towards cervical screening and cervical cancer. J Obstet Gynaecol 2002; 22: 421-2.

[27] Heidari HR, Mahmoudzadeh S, Sakhavar N. Breast cancer screening knowledge and practice among women in southeast of Iran. Acta Medica Iranica 2008; 46(4): 321-8.

[28] Milaat WA. Knowledge of secondary-school female students on breast cancer and breast self-examination in Jeddah, Saudi Arabia East Mediterr Health J 2000; 6(2-3): 338-44.

[29] Tfayli A, Temraz S, Abou Mrad R, et al. Breast cancer in low- and middle-income countries: an emerging and challenging epidemic. J Oncol 2010; 2010: 490631.

[30] Al-Meer FM, Aseel MT, Al-Khalaf J, Al-Kuwari MG, Ismail MFS. Knowledge, attitude and practices regarding cervical cancer and screening among women visiting primary health care in Qatar. EMHJ 2011; 17(11): 855-61.

[31] Al Sairafi M, Mohamed FA. Knowledge, attitudes, and practice related to cervical cancer screening among kuwaiti women. Med Princ Pract 2009; 18(1): 35-42. 